\title{
Development of an Analytical Method for Evaluating the Catalytic Active Sites of Titanium Silicalite Zeolite
}

\author{
Xiaoyan Huang1, Yan Xue1,2, Xin Gao1, Baojun Li' ${ }^{1}$, Yiqiang Wen ${ }^{1 *}$, Xiangyu Wang1* \\ ${ }^{1}$ Institute of Industrial Catalysis, College of Chemistry and Molecular Engineering, Zhengzhou University, \\ Zhengzhou 450001, China \\ ${ }^{2}$ Biological and Chemical Engineering College, Nanyang Institute of Technology, Nanyang 473004, China \\ Email: wenyiqiang@foxmail.com, xiangyuwang58@qq.com
}

Received April 2015

\begin{abstract}
A simple, quick, sensitive, accurate and precise method has been developed for evaluating the catalytic active sites of titanium silicalite-1 (TS-1). The catalytic active sites of titanium silicalite zeolite depend on the effectively active species (EAS) in TS-1 which react with specific substrates quickly. However, the EAS was hard to be evaluated with conventional instruments and techniques in the past. In this paper, the EAS was formed in TS-1 upon interaction with $\mathrm{H}_{2} \mathrm{O}_{2}$, and its presence could be confirmed by UV-vis spectroscopy which has an absorption peak at $385 \mathrm{~nm}$. The absorbance at $385 \mathrm{~nm}$ was found to be linearly related to time, and when the absorbance and the increasing rate of absorbance $(k)$ increased, the catalytic performance of TS-1 enhanced.
\end{abstract}

\section{Keywords}

Effectively Active Species (EAS), Titanium Silicalite Zeolite, UV-Vis Spectrum, Absorbance

\section{Introduction}

Titanium silicalite-1 (TS-1) was first reported by Taramasso in 1983 [1], which belonged to the MFI structure group. TS-1 possesses interesting catalytic properties, especially in reaction involving the use $\mathrm{H}_{2} \mathrm{O}_{2}$ as the oxidant, such as the hydroxylation of phenol [2]-[5], thiophene oxidation [6], epoxidation of cyclohexene [7], epoxidation of styrene [8], cyclohexane oxidation [9], epoxidation of propene [10] [11], ammoximation of cyclohexanone [12] [13]. Many studies have focused on the catalytic performance of TS-1, however, only a few works have tried to investigate the nature and the properties of the active species formed in TS- 1 upon interaction with $\mathrm{H}_{2} \mathrm{O}_{2}$ [14]-[16], and not all the framework titanium can contact with substrates quickly, due to the diffusion limitation by the size of the channels $(0.56 \mathrm{~nm} \times 0.53 \mathrm{~nm})$. This lack can be ascribed to severe experimental problems, mainly due to the presence of $\mathrm{H}_{2} \mathrm{O}$ and the lability of complexes formed by $\mathrm{H}_{2} \mathrm{O}_{2}$ on framework titanium in TS-1. Therefore, the effectively active species (EAS) in TS-1 is hard to be evaluated with IR

\footnotetext{
${ }^{*}$ Corresponding authors.
}

How to cite this paper: Huang, X.Y., Xue, Y., Gao, X., Li, B.J., Wen, Y.Q. and Wang, X.Y. (2015) Development of an Analytical Method for Evaluating the Catalytic Active Sites of Titanium Silicalite Zeolite. Journal of Materials Science and Chemical Engineering, 3, 1-6. http://dx.doi.org/10.4236/msce.2015.36001 
and NMR. The most probable technique to evaluate EAS in TS-1 is UV-vis spectroscopy because it is not affected by the presence of $\mathrm{H}_{2} \mathrm{O}$. According to the literature, TS- 1 contact with $\mathrm{H}_{2} \mathrm{O}_{2}$ water solution, a new band appears around $385 \mathrm{~nm}$ in the UV-vis spectrum. This band has already been assigned to the TiOOH on TS-1 [15] [16].

Herein we have dealt TS-1 with the mixed solution of $\mathrm{H}_{2} \mathrm{O}_{2}$ and methanol, the presence of the EAS has been confirmed by UV-vis spectroscopy. Epoxidation of propylene was used to assess the catalytic performance directly. The relationship between EAS in TS-1 and the catalytic performance has been systematically investigated to develop a quick analytical method for evaluating the catalytic active sites of titanium silicalite zeolite

\section{Experimental}

\subsection{Chemicals and Reagents}

Hydrogen peroxide AR grade $\left(\mathrm{H}_{2} \mathrm{O}_{2}\right)$, methanol AR grade $\left(\mathrm{CH}_{3} \mathrm{OH}\right)$, propene $\left(\mathrm{C}_{3} \mathrm{H}_{6}\right)$, ammonia AR grade $\left(\mathrm{NH}_{3}\right)$ were purchased from Tianjin chemical reagent factory. TS-1 was prepared following the procedure reported by Thangaraj [17].

\subsection{Instrumentation}

UV-vis spectra of the samples were obtained on Agilent Cary 5000 Spectrometer.

\subsection{Preparation of Samples}

\subsubsection{Preparation of Standard Samples}

A $0.5 \mathrm{~g}$ of sample was weighed and transferred into the sample cell. $0.6 \mathrm{~g} \mathrm{H}_{2} \mathrm{O}$ and $0.3 \mathrm{~g}$ methanol were added to the sample at $298 \mathrm{~K}$, and the mixture was confirmed by UV-vis spectroscopy. The propylene epoxidation was carried out in a stainless steel autoclave. In a typical run, $0.1 \mathrm{~g}$ of catalyst, $3.0 \mathrm{ml} 27.5 \mathrm{wt} \% \mathrm{H}_{2} \mathrm{O}_{2}$ and $24 \mathrm{ml}$ of methanol were fed into the reactor. The propylene was charged at constant pressure ( $0.6 \mathrm{MPa})$. The reaction was performed at $318 \mathrm{~K}$ under magnetic agitation for $60 \mathrm{~min}$. The residual $\mathrm{H}_{2} \mathrm{O}_{2}$ was checked by iodometric titrating and the product of epoxidation of propylene was analyzed on a GC 7890II gas chromatograph, using a flame ionization detector and a capillary column $(50 \mathrm{~m} \times 0.25 \mathrm{~mm} \times 0.25 \mu \mathrm{m}$, HT-superwax $)$.

\subsubsection{Preparation of Samples}

At $298 \mathrm{~K}, 0.5 \mathrm{~g}$ of TS-1 powder was mixed with solution of $0.6 \mathrm{~g}$ (43.8 wt\%) $\mathrm{H}_{2} \mathrm{O}_{2}$ and $0.3 \mathrm{~g}$ methanol, the paste fomed is placed in the sample holder. Then the UV-vis spcctrum of the paste mixture was quickly recorded on Agilent Cary 5000 Spectrometer and taken the change of the UV-vis spectrum every 2 minutes in the first 10 minutes.

\subsection{Analytical Method Validation}

The developed method was validated with respect to specificity, linearity, accuracy and reproducibility.

\subsubsection{Specificity}

Specificity is the degree to which the procedure applies to a single analyte and is checked in each analysis by comparing the blank UV-vis spectrum with the UV-vis spectrum obtained for the sample spiked with internal standard to trace out the interfering peaks. The specificity of the method was investigated by the analysis of the blank preparation spiked with sample, $\mathrm{H}_{2} \mathrm{O}$ and methanol were added.

\subsubsection{Linearity}

The linearity of the peak height response was determined by taking the change of the UV-vis spectrum at 385 $\mathrm{nm}$ every 2 minutes in the first 10 minutes. The linear regression coefficient and correlation coefficient were calculated.

\subsubsection{Accuracy}

The accuracy was assessed by studying the proportional relations between the absorbance at $385 \mathrm{~nm}$ and the 
catalytic performance of TS-1 by using two different catalytic performance of TS- 1 in the range of $80 \%$ to $100 \%$, and recovery study by standard addition method.

\subsubsection{Reproducibility}

Reproducibility of the method was determined by analyzing two times of TS- 1 samples. The mean, relative standard deviation (RSD) and sample of reproducibility were calculated.

\section{Results and Discussion}

\subsection{Specificity}

Finally, the specificity was established by comparing the blank UV-vis spectrum with the UV-vis spectrum obtained for the sample spiked with internal standard to trace out the interfering peaks. The specificity of the analytical procedure was achieved since no interference peak was observed (Figure 1, UV-vis spectrum 1). This band at $385 \mathrm{~nm}$ has already been assigned to the TiOOH on TS-1 [15] [16].

\subsection{Linearity}

The linearity of this method was determined by taking the change of the UV-vis spectrum at $385 \mathrm{~nm}$ every 2 minutes in the first 10 minutes. The plot of peak height against respective time of sample was found to be linear (Figure 2). The linearity was evaluated by linear regression analysis using least square method. The regression equations were found to be $Y=a X+b$ for samples and correlation coefficient of the standard curves were found to be more than 0.99 .

\subsection{Accuracy}

Accuracy of the method was found out by studying the proportional relations between the absorbance at $385 \mathrm{~nm}$ and the catalytic performance of TS- 1 by using two different catalytic performance of TS- 1 in the range of $80 \%$ to $100 \%$, and recovery study by standard addition method. It was observed (Table 1) that when the increasing rate $\mathrm{k}$ of absorbance at $385 \mathrm{~nm}$ increased, which means the forming rate of active species $\mathrm{TiOOH}$, the yield of propylene oxide improved and the absorbance increased, the conversion of $\mathrm{H}_{2} \mathrm{O}_{2}$ enhanced. And the conversion of $\mathrm{H}_{2} \mathrm{O}_{2}$ to the increasing rate of absorbance ratio was around 2.18, the yield of propylene oxide to the absorbance at $385 \mathrm{~nm}$ ration was around 152, the relative standard deviation (RSD) of ratio was $9.9 \%$ and 5.1\%, respectively. The known standard was added to sample- 3 and the results of recovery studies were shown in Table 2, the percentage recovery of the absorbance at $385 \mathrm{~nm}$ was $98.1 \%$ and the percentage recovery of the increasing rate $\mathrm{k}$ of absorbance was $99.5 \%$ which demonstrated that the method was highly accurate.

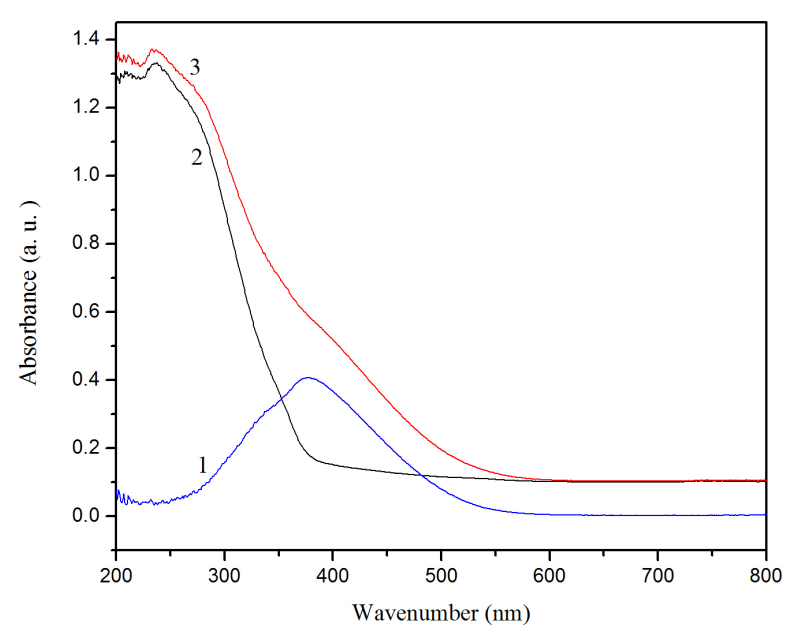

Figure 1. UV-vis spectra of the TS-1 samples. 1: the effectively active species; $2: \mathrm{H}_{2} \mathrm{O}$, methanol and TS-1; $3: \mathrm{H}_{2} \mathrm{O}_{2}$, methanol and TS-1. 


\subsection{Reproducibility}

Reproducibility data of sample is shown in Table 3. The relative standard deviation (RSD) of $\mathrm{k}$ was $1.02 \%$ and

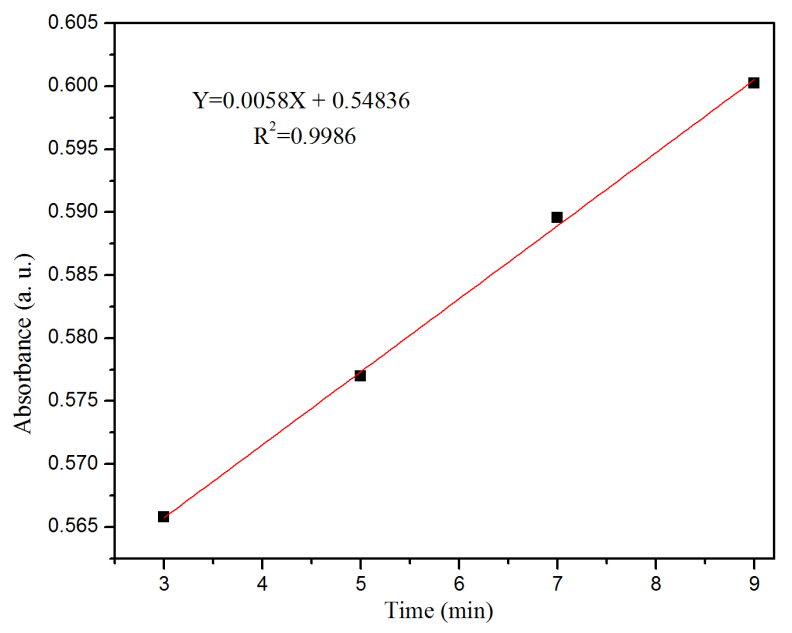

Figure 2. Linearity of the increasing rate of absorbance.

Table 1. Accuracy for evaluating the catalytic performance of TS-1.

\begin{tabular}{|c|c|c|c|c|c|c|}
\hline TS-1 & A & $\mathrm{k}\left(\min ^{-1}\right)$ & C (\%) & Y (\%) & $\mathrm{C} / \mathrm{A}$ & $\mathrm{Y} / \mathrm{k}$ \\
\hline 1 & 0.495 & 0.00559 & 99.7 & 87.8 & 2.01 & 157 \\
\hline 2 & 0.423 & 0.00620 & 99.1 & 90.3 & 2.34 & 146 \\
\hline \multicolumn{5}{|c|}{ Mean } & 2.18 & 152 \\
\hline \multicolumn{5}{|c|}{ RSD (\%) } & 9.9 & 5.1 \\
\hline
\end{tabular}

A stand for the absorbance at $385 \mathrm{~nm}$; $\mathrm{k}$ stand for the increasing rate of absorbance; $\mathrm{C}$ stand for the conversion of $\mathrm{H}_{2} \mathrm{O}_{2}$; $\mathrm{Y}$ stand for the yield of propylene oxide; RSD stand for relative standard deviation.

Table 2. Accuracy for the absorbance at $385 \mathrm{~nm}$.

\begin{tabular}{ccccc}
\hline TS-1 & 3 & 4 & 5 & Recovery (\%) \\
\hline A & 0.437 & 0.189 & 0.307 & 98.1 \\
$\mathrm{k}$ & 0.00360 & 0.00170 & 0.00264 & 99.5
\end{tabular}

A stand for the absorbance at $385 \mathrm{~nm}$; $\mathrm{k}$ stand for the increasing rate of absorbance; 3: sample-3; 4: standard sample; 5: 50 wt.\% sample-3 and 50 wt.\% standard sample.

Table 3. Reproducibility for the increasing rate of absorbance and absorbance.

\begin{tabular}{ccc}
\hline TS-1 & 6 & 7 \\
\hline $\mathrm{k}^{\mathrm{a}}\left(\mathrm{min}^{-1}\right)$ & 0.004900 & 0.00640 \\
$\mathrm{k}^{\mathrm{b}}\left(\mathrm{min}^{-1}\right)$ & 0.004830 & 0.00650 \\
${\text { Mean of } \mathrm{k}\left(\mathrm{min}^{-1}\right)}^{\text {RSD of } \mathrm{k}(\%)}$ & 0.004865 & 0.00645 \\
Absorbance $^{\mathrm{a}}$ & 1.02 & 1.10 \\
Absorbance $^{\mathrm{b}}$ & 0.45304 & 0.41476 \\
Mean of absorbance & 0.45780 & 0.41232 \\
RSD of absorbance (\%) & 0.45542 & 0.41354 \\
\hline
\end{tabular}

$\mathrm{k}^{\mathrm{a}}$ and $\mathrm{k}^{\mathrm{b}}$ stand for the increasing rate of absorbance that the first and second measured, respectively; Absorbance ${ }^{\mathrm{a}}$ and Absorbance ${ }^{\mathrm{b}}$ stand for the absorbance at $385 \mathrm{~nm}$ that the first and second measured, respectively. RSD stand for relative standard deviation. 
$1.10 \%$, respectively. The relative standard deviation (RSD) of absorbance was $0.739 \%$ and $0.417 \%$, respectively. The results indicated that this method was highly precise.

\section{Conclusion}

A rapid analytical method for evaluating the catalytic active sites of titanium silicalite zeolite has been developed. The method was found to be simple, quick, sensitive, accurate and precise. The catalytic performance of TS-1 showed a good relationship with the effectively active species in TS-1 which helped to appraise the catalytic performance of TS-1 quickly.

\section{Acknowledgements}

The authors are thankful to the management of Institute of Industrial Catalysis, College of Chemistry and Molecular Engineering, Zhengzhou University, for providing the necessary facilities and technical assistance to carry out the research work.

\section{References}

[1] Taramasso, M. and Donato, S. (1983) Preparation of Porous Crystalline Synthetic Material Comprised of Silicon and Titanium Oxidest. US Patent No. 4410501.

[2] Xin, H., Zhao, J. and Xu, S. (2010) Enhanced Catalytic Oxidation by Hierarchically Structured TS-1 Zeolite. The Journal of Physical Chemistry C, 114, 6553-6559. http://dx.doi.org/10.1021/jp912112h

[3] Zou, Y., Song, W. and Dai, C. (2013) Modification of Small-Crystal Titanium Silicalite-1 with Organic Base: Recrystallization and Catalytic Properties in the Hydroxylation of Phenol. Applied Catalysis A: General, 453, 272-279. http://dx.doi.org/10.1016/j.apcata.2012.12.027

[4] Wang, Y., Lin, M. and Tuel, A. (2007) Hollow TS-1 Crystal Formed Via a Dissolution-Recrystallization Process. Microporous and Mesoporous Materials, 102, 80-85. http://dx.doi.org/10.1016/j.micromeso.2006.12.019

[5] Ke, X., Li, X. and Chang, Z. (2007) Synthesis of Mesoporous TS-1 by Hydrothermal and Steam-Assisted Dry Gel Conversion Techniques with the Aid of Triethanolamine. Microporous and Mesoporous Materials, 106, 75-78. http://dx.doi.org/10.1016/j.micromeso.2007.02.034

[6] Zhu, Y., Hua, Z. and Zhou, X. (2013) CTBA-Templated Mesoporous TS-1 Zeolite as Active Catalytic in a Desulfrization Process: The Decreased Hydrophobicity Is More Favourable in Thiophene Oxidation. The Royal Society of Chemistry, 3, 4193-4198.

[7] Chen, L., Wang, Y. and He, M. (2011) Hydrothermal Synthesis of Hierarchical Titanium Silicalite-1 Using Single Template. Materials Research Bulletin, 46, 698-701. http://dx.doi.org/10.1016/j.materresbull.2011.01.015

[8] Huang, J., Liu, C. and Sun, D.H. (2014) Biosynthesized Gold Nanoparticles Supported over TS-1 toward Efficient Catalyst for Epoxidation of Styrene. Chemical Engineering Journal, 235, 215-223. http://dx.doi.org/10.1016/j.cej.2013.09.035

[9] Shia, C.F., Zhua, B. and Lina, M. (2011) Cyclohexane Mild Oxidation Catalyzed by New Titanosilicate with Hollow Structure. Catalysis Today, 175, 398-403. http://dx.doi.org/10.1016/j.cattod.2011.05.012

[10] Xiang, F.G., Duana, X.Z. and Qiana, G. (2014) Au Nanoparticles Deposited on the External Surfaces of TS-1: Enhanced Stability and Activity for Direct Propylene Epoxidation with $\mathrm{H}_{2}$ and $\mathrm{O}_{2}$. Applied Catalysis B: Environmental, 151, 396-401.

[11] Li, G., Wang, X. S. and Yan, H. S. (2001) Effect of Sodium Ions on Propylene Epoxidation Catalyzed by Titanium Silicalite. Applied Catalysis A: General, 218, 31-38. http://dx.doi.org/10.1016/S0926-860X(01)00607-X

[12] Yao, P.X., Wang, Y.Q. and Zhang, T. (2014) Effect of Sodium Ions in Synthesis of Titanium Silicalite-1 on Its Catalytic Performance for Cyclohexanone Ammoximation. Chem. Sci. Eng, 8, 149-155.

[13] Wu, X.X., Wang, Y.Q. and Zhang, T. (2014) Effect of TS-1 Treatment by Tetrapropyl Ammonium Hydroxide on Cyclohexanone Ammoximation. Catalysis Communications, 50, 59-62. http://dx.doi.org/10.1016/j.catcom.2014.03.003

[14] Sirijaraensreab, J. and Limtrakul, J. (2013) Mechanisms of the Ammonia Oxidation by Hydrogen Peroxide over the Perfect and Defective Ti species of TS-1 Zeolite. Physical Chemistry Chemical Physics, 15, 18093. http://dx.doi.org/10.1039/c3cp52682h

[15] Shetti, V.N., Srinivas, D. and Ratnasamy, P. (2004) Enhancement of Chemoselectivity in Epoxidation Reactions over TS-1 Catalysts by Alkali and Alkaline Metal Ions Ti-Peroxo Species in the TS- $1 / \mathrm{H}_{2} \mathrm{O}_{2} / \mathrm{H}_{2} \mathrm{O}$ System. Journal of Molecular Catalysis A: Chemical, 210, 171-178. http://dx.doi.org/10.1016/j.molcata.2003.09.014 
[16] Bonino, F., Damin, A. and Ricchiardi, G. (2004) Ti-peroxo Species in the TS- $1 / \mathrm{H}_{2} \mathrm{O}_{2} / \mathrm{H} 2 \mathrm{O}$ System. Journal of Physical Chemistry B, 108, 3573-3583. http://dx.doi.org/10.1021/jp036166e

[17] Thangaraj, A., Eapen, M. J., Sivasanker, S. and Ratnasamy, P. (1992) Studies on the Synhtesis of Titanium Silicalite, TS-1. Zeolites, 12, 943-050. http://dx.doi.org/10.1016/0144-2449(92)90159-M 